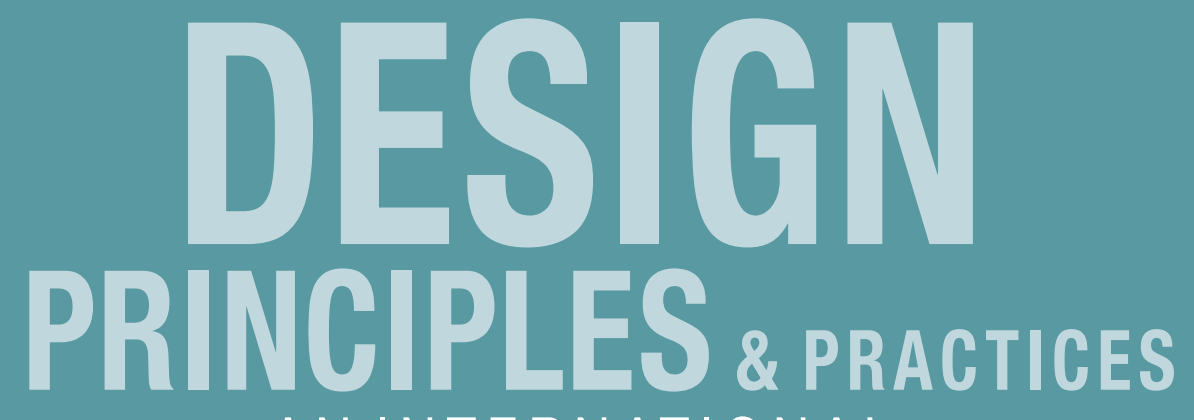

AN INTERNATIONAL

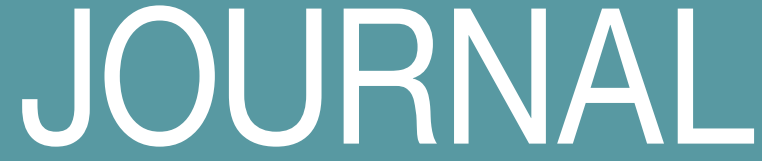

Volume 5

The Typographic City: Social Commitment and Graphic Design in the Urban Space in Two Late Modernist Italian Projects

Luciana Gunetti and Gabriele Oropallo 
DESIGN PRINCIPLES AND PRACTICES: AN INTERNATIONAL JOURNAL http://www.Design-Journal.com

First published in 2011 in Champaign, Illinois, USA

by Common Ground Publishing LLC

www.CommonGroundPublishing.com

ISSN: 1833-1874

(C) 2011 (individual papers), the author(s)

(c) 2011 (selection and editorial matter) Common Ground

All rights reserved. Apart from fair dealing for the purposes of study, research, criticism or review as permitted under the applicable copyright legislation, no part of this work may be reproduced by any process without written permission from the publisher. For permissions and other inquiries, please contact

<cg-support@commongroundpublishing.com>.

DESIGN PRINCIPLES AND PRACTICES: AN INTERNATIONAL JOURNAL is peerreviewed, supported by rigorous processes of criterion-referenced article ranking and qualitative commentary, ensuring that only intellectual work of the greatest substance and highest significance is published.

Typeset in Common Ground Markup Language using CGPublisher multichannel typesetting system

http://www.commongroundpublishing.com/software/ 


\title{
The Typographic City: Social Commitment and Graphic Design in the Urban Space in Two Late Modernist Italian Projects
}

\author{
Luciana Gunetti, Politecnico di Milano, Italy \\ Gabriele Oropallo, University College London, UK
}

\begin{abstract}
Between the late nineteen-sixties and the late nineteen-eighties, the field of Italian graphic design saw many practitioners attempt to test and apply ideas more immediately related to the social function of design. Their new approach to design tried to overtly oppose the rampant consumerist models with a very constructive, empirical approach that to some extent represented a novelty in the contemporary history of Italian design that favoured the balance of forces rather than direct opposition. A central event in this context is the development of what for lack of better terms can be called "urban typography," a form of graphic design that intervened on the whole surface of the urban space. This paper looks at two examples of such interventions and at the historical and theoretical framework in which they were developed. These limited, practical interventions were structurally aimed at functioning as a mediation between institutions and community, with a focus on inclusion and on the local dimension. They were articulated as single projects rather than general theorisations and programmatic manifestos. This paper subsequently argues that the experience of "urban typography" has to be framed in the contemporary European cultural milieu which saw, on the one hand, a modernism appropriated by ideologies and corporations and, on the other, the logic of the grand, radical intervention revealing its utopian character. Urban typography, in other words, was an alternative to the polarisation between ideology and professionalisation. It offered graphic designers who embraced this concept an alternative to ideological commitment and professional mannerism.
\end{abstract}

Keywords: Graphic Design, Planning, Post-war, Politics, Italy, Exhibition, Design, Albe Steiner, AG Fronzoni, Commitment, Typography, Politics, City

\section{Introduction}

$\mathrm{M}$

ODERN DESIGN'S PERCEIVED failure to make a real difference in Italian society during the post-war period ${ }^{1}$ was a disappointment that acted as a stimulus toward experimentation into new methods and territories. The public sector in particular provided some space for the experimentation of new forms of design with a social emphasis. As cities grew in size and complexity, information design became as crucial and important as paved roads for their navigation.

Although different in extension over time and space, these projects did nevertheless share similar socio-linguistic concerns and spatial strategies. They were aimed at the entire community, and their scope was horizontal and inclusive. By using the entire city as a canvas,

\footnotetext{
${ }^{1}$ A particularly useful author on these issues is architectural historian Manfredo Tafuri. See his "Desing and Technological Utopia" in Emilio Ambasz (ed), Italy: The New Domestic Landscape (New York: MoMA, 1972) and Architecture and Utopia: Design and Capitalist Development (1973, then Boston: MIT, 1979).
}

Design Principles and Practices: An International Journal 
politically and socially committed graphic designers managed to overcome the constraints that inherently limited the reach of post-war two-dimensional artifacts.

These limited, practical interventions were structurally aimed at functioning as a mediation between institutions and community with a focus on inclusion and on the local dimension. They were articulated as single projects rather than general theorizations and programmatic manifestos. To some extent, this approach represented a novelty in the history of contemporary Italian design in that it pursued a balance of forces rather than direct opposition, as in the case of radical design, or imposition on the environment, as it had happened with large modernist housing programs.

One can call this approach "urban typography," in that it is a general dispersion of graphic design over the whole surface of the urban space, with the designers breaking down information into constitutive units and rearranging them as typographic elements in the urban space, as on a white page. Rather than adding a further layer of commentary to the stratified text that constitutes the built environment, urban typography aimed at facilitating the navigation of the city, at providing the citizens with the visual tools to interact with its complexity. Graphic designers who worked on the urban space treated it in the same way typographers treat text when they set a page for print: highlighting and emphasizing certain elements to allow the reader to swiftly browse through the textual mass and find relevant pieces of information.

In this article we shall be looking at two examples of such interventions and at the historical and theoretical framework within which these projects were developed. Albe Steiner ${ }^{2}$ and $\mathrm{AG}$ Fronzoni ${ }^{3}$ as graphic designers produced work characterized by very different formal and aesthetic values, but they both saw their design ingrained in the modernist tradition and were politically and socially committed. Also, they had both been involved in the design of radical publications in the wake of the Second World War, Steiner designing Il Politecnico 4 and Milano Sera and Fronzoni the less known, but not less ambitious Punta. ${ }^{5}$ These experiences allowed them to develop a certain theatre-like approach to the arrangement of the elements within the frame, with the designer acting as a direction. They later experimented other scales of action curating the exhibition design for private manufacturers and department stores as Milan's La Rinascente (Steiner) and shows for museums and art galleries (Fronzoni). Both designers increasingly expanded their sphere of action. Steiner designed a sign system for the Cortina Winter Olympics in 1956, while Fronzoni built a solid reputation working with museums and art galleries, as well as designing temporary spaces for public events. Steiner's corporate image project for the Urbino municipality in 1968 and Fronzoni's work on the Art and City event program in Genoa in 1979, however, were unique in the Italian landscape in the subtly radical way they engaged the public. In Steiner's case, the project was the product of an exceptional unity of intentions between the designer, his students and

\footnotetext{
${ }^{2}$ The best introduction to Albe Steiner are two collections of his writings and his work: Il mestiere di grafico (Turin: Einaudi, 1978) and Il manifesto politico (Rome: Editori Riuniti, 1978).

${ }^{3}$ On Fronzoni, see Gabriele Oropallo, "Design as a Language without Words: The Graphic Design of AG Fronzoni", in Grace Lees-Maffei, Writing Design: Words and Objects (Oxford: Berg, 2011) or Christian Aichner and Bernd Kuchenbeiser, AG Fronzoni (Baden: Verlag Lars Müller, 1997).

${ }^{4}$ Il Politecnico (1945-1947) founded and directed by Elio Vittorini was a progressive but not organic political and cultural review, one of the most important amongst the journals published in the immediate post-war period in Italy. It was initially designed to be also a mural journal, affixed to the walls of the cities as a poster.

${ }^{5}$ Punta was founded and directed by AG Fronzoni and published in Brescia in the Spring and Summer of 1947.
} 
their client; in Fronzoni's case, a common concern toward a radical rethinking of the exhibition media, shared by designer, artists and the client, the municipality

\section{Urbino 1968: Grafica di Pubblica Utilità}

As early as 1966, in an article on "Cultural formats" published on the Parete magazine, Steiner pointed out that the "form" of public art should not be designed up front but left open to incorporate not only a dialogue between objects (in this case, posters) and public, but also between the designer and the clients. ${ }^{6}$ What Steiner initially labelled as "public art" was a form of design practice which came to be known as grafica di pubblica utilità after a wording that can be translated as both "graphic design for the public benefit" and "graphic design as a public service".

This expression was used for the first time at the end of the nineteen-sixties by Albe Steiner to describe the project he worked on with a group of his students in the ancient university town of Urbino, on the Italian east coast, at whose Applied Art Institute he was at that time teaching. ${ }^{7}$ Therefore, the project was the result of an informed acquaintance with the urban space of Urbino. This included also an intense collaboration and exchange with the architect Giancarlo De Carlo, himself a great promoter of civil inclusion in his work, who had worked in 1964 on the master plan of Urbino. ${ }^{8}$ In 1967 Steiner also designed the layout of De Carlo's detailed study of the urban history of the town. ${ }^{9}$

The project consisted in the creation of an integrated system designed to mediate communication between the local institutions and the public, that included posters, street signs, urban orientation aids, publications and a new city emblem. The original wording used by Steiner referred to the necessity to substitute "heraldic symbols of ownership with signage that is actually useful to the public." One of the key terms in Steiner's writings is the adjective "public", a hint to the two legitimate clients of the commission, public institutions, as well as the citizenship. On the one hand, local administrations, organizations and on the other, the users, the receivers of information. On the other hand, the term "utility" underlines the ethical quality of the work, which is subsequently characterized as a basic service, as the provision of an essential good: information.

\footnotetext{
${ }^{6}$ Albe Steiner, "Formato Cultura", Parete 6 (February-May 1966). See also Giovanni Anceschi, "Circostanze e istituzioni della grafica di pubblica utilità", in Giovanni Anceschi, Prima biennale della grafica. Propaganda e Cultura (Milan: Mondadori, 1984). Albe Steiner's concept of “Culture Format” was reminiscent of El Lissitzky's 1923 visionary manifesto, originally published on Merz 4 in which he claimed that the space of the book, as all designed space, had to be a direct emanation of the tensions and forces included within the content. Similarly, for Steiner, the "Culture Format" is "the result of a synthesis that cannot come into being without culture and and maximum freedom of expression."

${ }^{7}$ Albe Steiner, "Dall'araldica di proprietà al segno di pubblica utilità": Albe Steiner, "Contributo della grafica per una migliore educazione statale" in Il mestiere di grafico (Turin: Einaudi, 1978).

${ }^{8}$ On Giancarlo De Carlo see John McKean, Giancarlo De Carlo: Layered Places (Stuttgart: Menges, 2004) or Maria Rita Guccione and Alessandra Vittorini (eds.), Giancarlo De Carlo: Le ragioni dell'architettura (Milan: Electa, 2005). Also by McKean, on De Carlo's experimentations with participatory planning and architecture, see "Giancarlo De Carlo et l'experience politique de la participation", in Jean-Lucien Bonillo, Claude Massu and Daniel Pinson (eds.), La Modernité Critique, autour du CIAM 9, d'Aix-en-Provence - 1953 (Marseille: editions Imberton, 2006).

${ }^{9}$ Giancarlo De Carlo, Urbin La storia di una città e il piano della sua evoluzione urbanistica (Padova, Marsilio, 1966). Steiner had already worked on the corporate identity for the Urbino University Colleges. De Carlo's master plan for Urbino was perhaps a stimulus for Steiner towards a radical rewriting of the design school curriculum.
} 
The project was presented in a "working exhibition and conference" on 24-25th May 1969, (Fig. 1) which Steiner presented as an ambitious program to realize an intervention on the entire urban and scape understood as a collective project of corporate identity. ${ }^{10}$
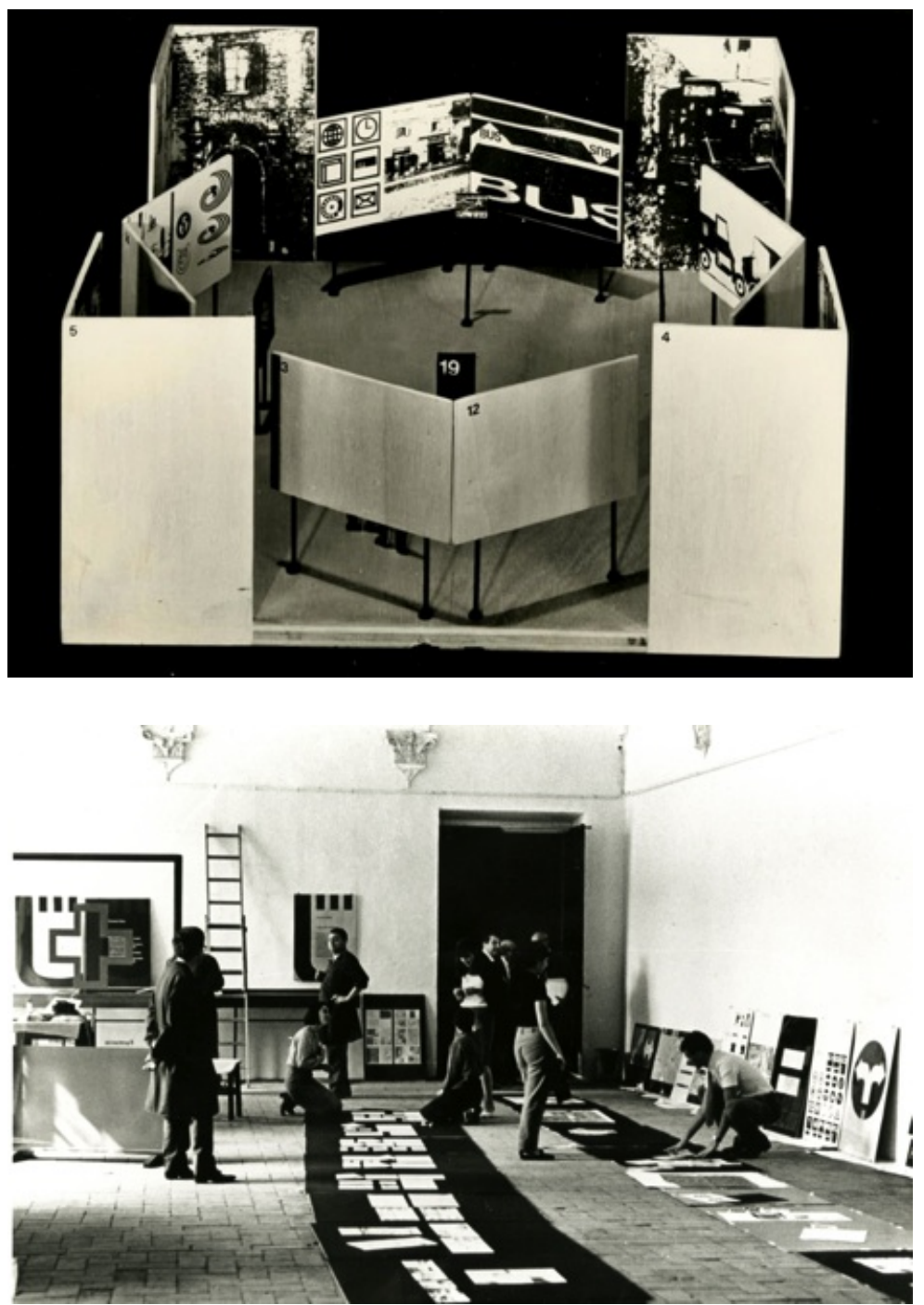

Fig. 1: Urbino Conference-exhibition, 24-25 May 1968. Steiner's Students While Mounting the Exhibition. Below, an "Environment Model" used to Immerse the Viewer into the Sign System

\footnotetext{
${ }^{10}$ Albe Steiner, "Mostra convegno di lavoro. Grafica e segnaletica in un centro storico", Linea Grafica 3 (MayJune 1969).
} 
The role Steiner and his students had to play was the one for which Umberto Eco in those years coined the expression "operative practice persuaders". ${ }^{11}$ Indeed, Steiner also launched in parallel a new course at the Urbino Applied Art Institute on "Sign system and graphic design for old town centers". It is useful to see the different kind of artifacts that were compulsory coursework: 1. From heraldic symbols to publicly useful signs; 2. Visual communication on public transport; 3 . Sign systems for cultural heritage; 4 . Sign systems for public service corporations; 4 . Corporate identity for municipalities.

Remarkably, Steiner and his students were working at the same time on the image for the 1968 Milan Triennale (T14), whose topic was "mass production" (Il grande numero). Rather than the product of an ideological choice, in other words, the Urbino project seems to be the result of a methodological consideration, a bottom-up approach in which the context provides the designer with the raw material, as opposed to an imposition of the designer's conceptual world on the environment.

Steiner's approach consists in disassembling to rearrange. The elements already collected in the overall image of the city are taken apart and reorganized, and in the process they acquire new meanings. The method, nevertheless, is not an adaptation, a post-modern use of elements already known to the user in a Pavlovian fashion, that is to inspire certain reactions. It is a sort of vegetative methods, with the basic elements distilled from the original unity and developed into new sign/meaning units. The letter "U", for instance, which appears in most of the identity materials, is a concise version of the actual shape of the medieval city-state emblem, which very comfortably also doubles as initial of the city's name. In Steiner's project, however, the "U" logo is not empty filled up again with symbols and fragments, subsequently becoming again a contemporary heraldic shield. The identity of the Urbino municipality is treated as "divisible unity": the original geometrical elements that make up the medieval symbol are disassembled and rearranged through a process that goes from a synthesis of the old heraldic identity to a new, wider public identity. The progress is from the identity of the municipality to the newsletter and the exhibition design.

These processes of distillation and recombination are painstakingly photographed and recorded by Steiner. Sketches, studies, dummies, everything is collected in Steiner's archive. This is not only a forward-looking process, but also a very contemporary one. Indeed, the project reached its climax through 1969 exhibition/conference. In this occasion, the artifacts were not only collected and put on display in three sections: graphics, signs, publications. Most importantly, they were also arranged along a narrative path, which highlighted in its educational purpose the designer's aim to render the sign system accessible, expandable and sustainable.

\section{Genoa 1979: Arte e Città}

In 1979, AG Fronzoni was commissioned a coordinate image project for a program of cultural events that took place over two seasons in the city of Genoa (Fig. 2). The program, called Immagini per arte e città (Images for Art and the City), included the organization and the promotion of a series of contemporary cultural events throughout the entire city.

\footnotetext{
${ }^{11}$ In the original Italian "Stimolatori di pratiche persuasive". Umberto Eco, "Un contributo critico all'Universitas project”, Argomenti e immagini di design 5 (May-June 1972), p. 82.
} 
The project was the result of a series of unique conditions, first of all the new left-wing local administration which ruled the city from $1978 .{ }^{12}$ The new administration chose a museum as its headquarters, declaring through this foundational act its intention of bringing culture to the very core of its politics, to make it a channel for communication with the citizenship. The purpose of the Arte e città project was to bring culture outside the institutional sphere, literally on the street, in to the urban space, and engage the citizenship. Differently from the Urbino project, however, Arte e città was not designed to be a long-standing, organic intervention on the urban layout. Culture was meant to become a forum to which the individuals could take part, ultimately stimulating individual consciences, but also consolidating consensus around the new administration, rather than the institutions in general.

Fronzoni's declared objective was to solve the problem of the "untidiness of the urban image." Looking at the pictures of the city during the program, Fronzoni's intervention, with his trademark monochrome posters, appears as an attempt to lay out a grid that overlaps with the existing urban space, providing structure to it and smoothing the striated space of an old historical city centre. Genoa's city centre, mostly organically grown and intensified during the seventeenth century, has been sometimes called a prototypical case of Italian abusivismo. ${ }^{13}$

The project was a major attempt to create a series of integrated, coordinated communication artifacts, whose coherence was based on the dialectics between structural elements stay unaltered throughout the series (sizes, chromatic and formal values, Univers typeface) and others that continuously change (grid, compositional values). Interestingly, the grid is usually an element that stays unaltered throughout large projects to provide continuity. In the Genoa project, on the contrary, the grid fluidly changes from poster to poster and continuity is entrusted to other elements, as the typeface Univers, which is more readable than Futura when used in street signs and advertising. ${ }^{14}$ The posters that form the Arte e città series were used by Fronzoni as a manifesto on his idea of the graphic designer: a figure of mediation between some crude material (communications, information pieces) and the final user. A professional whose main target is to actively design a path for everyone to an immaterial but extremely precious good: information. From this point of view, his brief was similar to Steiner's as the latter approached with his students the Urbino project, a decade before.

The typographic space of the Arte e città posters, as a result, is made smooth from striated, exactly as in the urban scale of the whole space of the city on which the project is applies. Since the constraint is not the grid, but the formal values, the compositional language adopted by Fronzoni has to be always self-assured, firm, sharp. This tension is palpable in these posters, with elements often in contrast (arrows pointing in different directions, broken letters, segmented paragraphs of text), and expanding into the typographic space by way of this very antagonism of empty and full, centre and periphery, limited and unlimited.

The same poetics emerges even more clearly in the design of the exhibition displays. In this case, the elements that stay unaltered are the exhibition stands, while the content of the show itself is supported and interpreted, made legible through the apparent stillness of the

\footnotetext{
${ }^{12}$ See Mario Guaraldi: Genova: la cultura di una politica - storia per immagini di cinque anni di lavoro culturale nella città (Milan: Electa, 1981).

${ }^{13}$ This term that refers to the post-war widespread practice of building without planning permission, which has plagued many parts of the country's historical and natural landscape.

${ }^{14}$ Univers was a sans-serif typeface designed by Adrian Frutiger in 1954. Released by Deberny \& Peignot in 1957 , it was acquired by Haas foundry in 1972, subsequently becoming more immediately available. Previously, Fronzoni's studio had predominantly used Helvetica or Futura.
} 
stands. Fronzoni designed only three exhibition systems, made of modular elements that provided for infinite arrangement and layout possibilities. The rationale behind the design of all of the three systems is the attempt to move as farther as possible away from the architectural framework, creating room for an exhibition space by effect of this gesture. This architectural behavior brings to mind another space, the Centre Pompidou in Paris, designed only three years earlier by Renzo Piano and Richard Rogers with a similar aim to extract the exhibition space from any intrusion, be structural (service spaces of the building) or external (the historical urban texture). This empty space invites the user to make use of it, and subsequently to develop their nature by experience. As a formal constituent is therefore very similar nature to distance between the message and the viewer that characterizes Fronzoni's posters, which is a space for speculation and critical understanding.
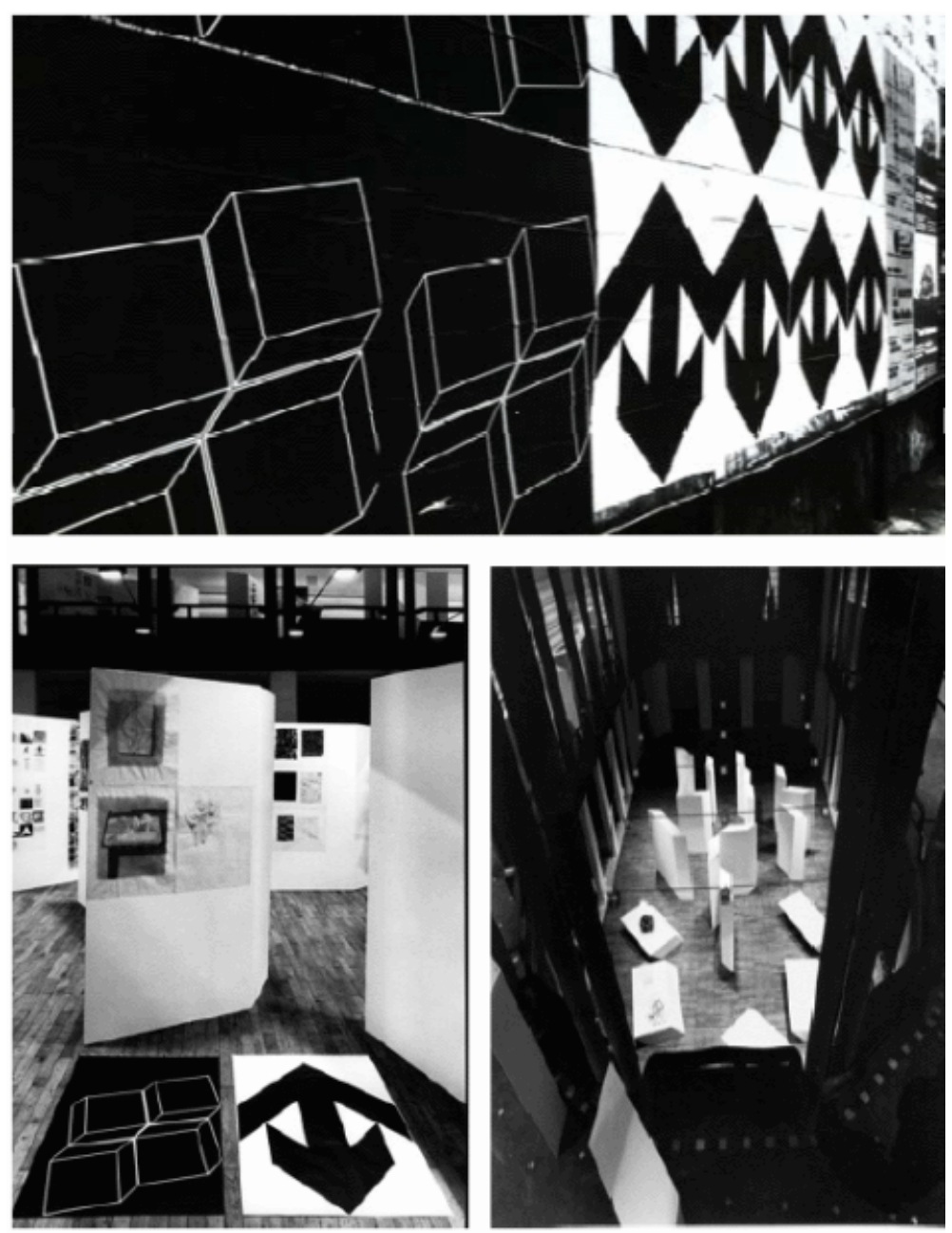

Fig. 2: AG Fronzoni, Posters and exhibition design for Art and Education, a Research Seminar and Exhibition Part of the Arte e città series, Genoa, 1979 


\section{Conclusion}

After the end of the war both Steiner and Fronzoni had been engaged (albeit to different extents and with different degrees of success) in the ideation and design of progressive publications. These forward-thinking, radical journals and publishing houses aimed at functioning as fora of discussion and hubs for the diffusion of culture and ideology within society at large. Their effect, however, was undermined by several constrains. First of all, the simple fact that a journal had to be purchased to be accessed and activate the ideas and opinions it carried. Other important limits were also literacy and geographical reach.

These projects of urban typography share one particular aspect, which is their virtual limitlessness. They were created by graphic designers and their basic elements were twodimensional artifacts, but nevertheless they were designed to unfold and function into the three-dimensional (or even poly-dimensional considering the temporary nature of the poster) space of the city.

Another crucial element is that authorship is softened or muted altogether: rather than superimposed, systems of signs are combined, enmeshed with the built environment until they become part of the urban fabric, as structural as the material. Finally, this experience has to be framed in the contemporary European cultural milieu which saw, the grand narrative of modernism losing its appeal. On the one hand, its aesthetics was being appropriated by ideologies and corporations. On the other hand, as we have seen, the logic of the grand, radical intervention had revealed its utopian character.

This kind of public, useful graphic design was a way out of this impasse. It was an alternative to the polarization between ideology and professionalization.

Indeed, ideological commitment after the season of radical design had reached a stage at which it basically offered only two strategic options: sabotage or resignation. The other end the spectrum was professional mannerism. Most graphic designers - as demonstrated by their keen support of the Charter of Graphic Design ${ }^{15}$ - a self-generated code of practice published in 1989 - saw with suspicion the emphasis on creativity, the totemization of the beautiful that had and still has largely colonized all spheres of design in Italy, especially product and interior. $^{16}$

While the modernist rigor truly represented a limit to the Italian product design system, which aimed at a niche public, its basic and original infatuation with standardization as inclusion was still valid for many graphic designers. It was not a perceived as a limit to innovation, but as an everlasting inspiration. While mass production was antithetic to the culture of niche design, of exclusive furniture pieces, this constraint affected to a lesser extent the work of those graphic designers who were interested in producing visual materials aimed at mediating information to a large number of users.

\footnotetext{
${ }^{15}$ Giovanni Anceschi et al., "Charter of Graphic Design: Proposal for a Debate on Visual Communication Design", Design Issues 8, 1 (Autumn, 1991).

${ }^{16}$ One may look at furniture design, in particular, and at the iconization of an object as the armchair: many product designers are identified by their most famous chair, often used in publications and exhibitions as a shortcut to their style and design philosophy. By the early nineteen sixties, after the struggle for international recognition of the "neo-liberty," the path towards the multilingualism of radical and post-modern was wide open, with Italian products arriving right on time and in the right amount to gain cult status.
} 


\section{About the Authors}

\section{Dr. Luciana Gunetti}

Luciana Gunetti is an architect and a design research consultant based in Milan, Italy. She was awarded her $\mathrm{PhD}$ in Industrial Design and Multimedia Communication from the Politecnico di Milano, after completing a post- graduate course in Industrial Design at the SSDI School of the Federico II University of Naples. Since 2000 she has been involved in research projects in theory and history of Communication Design, also collaborating with the Faculty of Design of the Politecnico di Milano on a regular basis. She also worked in AG Fronzoni's famous practice-workshop in Milan, inventorying part of the archive. Her long-term research projects include the mapping and designing of new info-display systems for the archives of several protagonists of Italian communication design history. She is currently the acting curator of the Albe and Lica Steiner Archive, an important collection of artifacts privately donated and managed by the Department of Architectural Design of the Politecnico di Milano.

\section{Gabriele Oropallo}

Gabriele Oropallo lives and works in London, England, where he is completing a $\mathrm{PhD}$ on social and political commitment and graphic design in late Modernism at University College London. Looking at examples from the late modernist canon, his research assesses the extent to which design and social commitment can be associated, and argues that the expansion of graphic design into the urban space provided an opportunity for designers to overcome the impasse between radicalism and professional mannerism. In 2006-2008 he was awarded a Marie Curie fellowship by the European Commission for his research at the UCL Centre for European Studies. He has published and presented on his research and allied topics internationally, also being a guest lecturer at the Carnegie Mellon University, Pittsburgh, USA in April 2008 and at the University of Reading, England, in November 2010 and February 2011. In May 2010 he organised "Critical minds: Critical spaces", an international symposium on critical design, architecture and planning at University College London. In March 2011 he curated and chaired "The Ethics of Graphic Design? Social Commitment and Visual Communication", a public seminar. In parallel with his academic activities, he is involved in other projects aimed at bringing research and scholarship to wider audiences, as curating, photography and documentary film-making. 



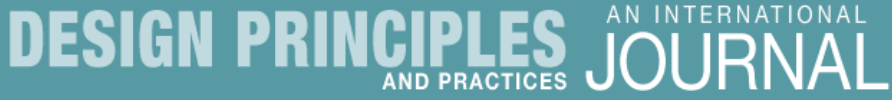

\section{Editor}

Bill Cope, University of Illinois, Urbana-Champaign, USA.

\section{Editorial Advisory Board}

Genevieve Bell - Intel Corporation, Santa Clara, USA.

Michael Biggs - University of Hertfordshire, Hertfordshire, UK.

Thomas Binder - Royal Danish Academy of Fine Arts, Copenhagen, Denmark.

Jeanette Blomberg - IBM Almaden Research Center, San Jose, USA.

Eva Brandt - Danmark Designskole, Copenhagen, Denmark.

Peter Burrows - RMIT University, Melbourne, Australia.

Monika Büscher - Lancaster University, Lancaster, UK.

Patrick Dillon - Exeter University, Exeter, UK.

Michael Gibson - University of North Texas, Denton, USA.

Mary Kalantzis - University of Illinois, Urbana-Champaign, USA.

Loredana Di Lucchio - Sapienza Universita di Roma, Rome, Italy.

Judith Gregory - IIT Institute of Design, Chicago, USA; University of Oslo, Norway.

Clive Holtham - City of London University, London, UK.

Lorenzo Imbesi, Carleton University, Ottawa, Canada.

Hiroshi Ishii - MIT Media Lab, Cambridge, USA.

Gianni Jacucci - University of Trento, Trento, Italy.

Klaus Krippendorff - University of Pennsylvania, Philadelphia, USA.

Terence Love - Curtin University, Perth, Australia.

Bill Lucas - MAYA Fellow, MAYA Design, Inc., Pittsburgh, USA.

Ezio Manzini - Politecnico of Milano, Milan, Italy.

Mario Minichiello - Birmingham Institute of Art and Design, Birmingham, UK.

Julian Orr - Work Practice \& Technology Associates, Pescadero, USA.

Mahendra Patel - Leaf Design, Mumbai, India.

Toni Robertson - University of Technology Sydney, Sydney, Australia.

Terry Rosenberg - Goldsmiths, University of London, London, UK.

Keith Russell - University of Newcastle, Callaghan, Australia.

Liz Sanders - Make Tools, USA.

Maria Cecilia Loschiavo dos Santos - University of São Paulo, São Paulo, Brazil.

Lucy Suchman - Lancaster University, Lancaster, UK.

Ina Wagner - Technical University of Vienna, Vienna, Austria.

Please visit the Journal website at http://www.Design-Journal.com for further information about the Journal or to subscribe. 


\section{The Design Principles \& Practices Community}

This knowledge community is brought together by a shared interest in the process of design and their conceptual foundations. The community interacts through an innovative, annual face-to-face conference, as well as year-round virtual relationships in a weblog, peer reviewed journal and book imprint - exploring the affordances of the new digital media. Members of this knowledge community include academics, designers, administrators, educators, consultants and research students.

\section{Conference}

Members of the Design Community meet at the International Conference on Design Principles and Practices, held annually in different locations around the world. The Design Conference was held at Imperial College London, in 2007; in conjunction with the University of Miami, Florida, USA in 2008; at Technical University Berlin, Germany in 2009; at the University of Illinois at Chicago, USA in 2010; and at Sapienza University of Rome, Italy in 2011. In 2012, the conference will be held at the University of California, Los Angeles, USA.

Our community members and first time attendees come from all corners of the globe. Intellectually, our interests span the breadth of the field of design. The Conference is a site of critical reflection, both by leaders in the field and emerging scholars and practitioners. Those unable to attend the Conference may opt for virtual participation in which community members can either submit a video and/or slide presentation with voice-over, or simply submit a paper for peer review and possible publication in the Journal.

Online presentations can be viewed on YouTube.

\section{Publishing}

The Design Community enables members of its community to publish through three media. First, by participating in the Design Conference, community members can enter a world of journal publication unlike the traditional academic publishing forums - a result of the responsive, non-hierarchical and constructive nature of the peer review process. Design Principles and Practices: An International Journal provides a framework for double-blind peer review, enabling authors to publish into an academic journal of the highest standard.

The second publication medium is through the book series On Design, publishing cutting edge books in print and electronic formats. Publication proposals and manuscript submissions are welcome.

The third major publishing medium is our news blog, constantly publishing short news updates from the Design Community, as well as major developments in the field of design. You can also join this conversation at Facebook and Twitter or subscribe to our email Newsletter. 